\title{
Synthesis and Use of Versatile [1.1.1]Bicyclopentylaldehyde Building Blocks
}

\author{
Dániel Lasányi, Dániel Máth, Gergely L. Tolnai* \\ Institute of Chemistry, Eotvos Lorand University, Pazmany P. stny. 1/a.
}

\begin{abstract}
The [1.1.1] bicyclopentane (BCP) motif is an emerging scaffold in medicinal chemistry due to its bioisosterism to 1,4phenylene and 1,2-alkynyl functions. Current drawback of their use is the lack of stable versatile synthetic building blocks. Aldehydes are amongst the most useful functionalities in organic chemistry. In this paper a simple one-pot procedure from aryl-halides and [1.1.1]propellane is described. Preparation of various BCP molecules is conducted to showcase the versatility of these stable intermediates.
\end{abstract}

Modern drug design increasingly facing towards 3-dimensional molecular scaffolds, as much as the chemical space within 2dimensional has been occupied. This concept is called "escape from flatland", ${ }^{1-2}$ and provided many interesting new scaffolds for drug discovery in recent years. Analogue based drug discovery is one of the main approaches in the delicate science of drug design. ${ }^{3}$ The concept can benefit from the idea of bioisosteres, when two different molecules, or functional groups has very similar impact on living organisms. ${ }^{4}$ One of the promising 3D scaffolds in this area is the [1.1.1]bicyclopentane (BCP). Over offering a novel structural motif in drug discovery, $\mathrm{BCP}$ has the advantage of being a promising bioisostere of 1,4-phenylene and 1,2-alkynyl functions. The utility of this functional group has been showcased on many occasions with several bioactive compounds, such as for example BCP-Darapladib, a mGlu antagonist or BCP-Tazarotene (Figure 1)..$^{5-15}$
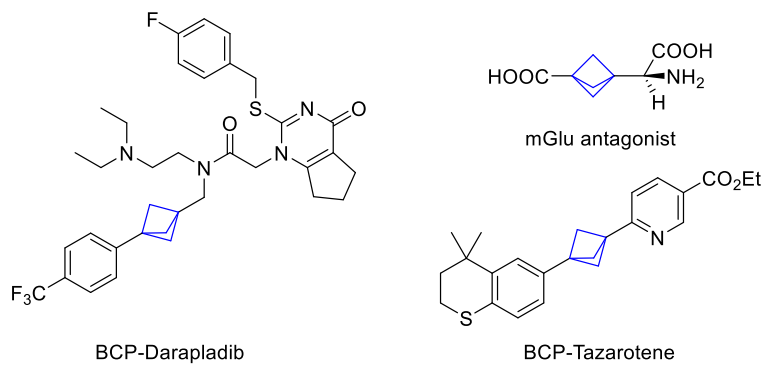

Figure 1, Selected BCP containing bioactive molecules

It is not surprising, that the popularity of this scaffold is increasing in industrial research, as proven by the number of patents in recent years. In contrast, their synthesis is not straightforward. The main pathway to the synthesis of this functionality is generally through [1.1.1]propellane. ${ }^{16-19}$ However [1.1.1]propellane is not difficult to synthesize, it is not suitable for long-time storage as feedstock chemical. This interferes with the widespread application of this interesting scaffold in medicinal chemistry laboratories, therefor the existence of stabile bicyclopentane containing reagents would be highly desirable.

Recent developments of practical bicyclopentyl building blocks mainly involve heteroatom substituted bicyclopentanes. This might be a boronic acid derivative, ${ }^{20-23}$ halo-substituted $\mathrm{BCP},{ }^{24}$ or the useful $\mathrm{N}$ analogues. ${ }^{25-32} \mathrm{~A}$ series of interesting approach was developed by Uchiyama. Upon silaboration of propellane, the resulting product has proven to be generally applicable in cross-coupling reactions. ${ }^{33}$ Alternatively, the well-known, but fragile 1,3-diiodobicyclopentane can be encapsulated in cyclodextrins, to obtain a stable source of propellane. ${ }^{34}$ As a carbon substituted alternative, very recently the practical largescale synthesis of bicyclo[1.1.1]pentane-1,3-dicarboxilyc acid was solved by Mykhailiuk. ${ }^{35}$ Synthesis of C-substituted BCP-s was investigated by the group of Walsh, leading to mono substituted [1.1.1]bicyclopentanes. ${ }^{36-37}$

Not surprisingly, many of the pathways to bicyclopentane containing molecules proceeds via a $\mathrm{BCP}$-aldehyde intermediate, ${ }^{10}$ $15,38-42$ as aldehydes are amongst the most versatile functions in organic synthesis. In contrast the synthesis of these molecules usually involves lengthy synthesis, and no precedence of their general synthesis is showcased in the literature. These routes are usually involving oxidative-reductive pathways, as exemplified in Scheme $1 .{ }^{40} \mathrm{With}$ the available procedures it usually takes several days to obtain BCP aldehyde.

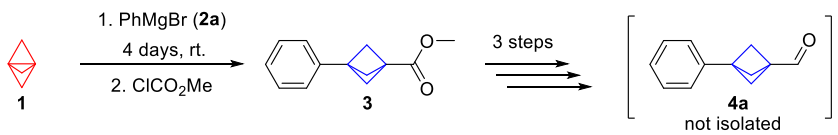

Scheme 1, Literature protocol for BCP aldehyde synthesis

Historically, the addition of Grignard reagents to the central bond of [1.1.1]propellane was known. ${ }^{43-44}$ An important development on this field was Knochel's discovery, that in overheated $\mathrm{Et}_{2} \mathrm{O}$ the reaction rate is several times faster, allowing the practical synthesis of BCP Grignard reagents $(\mathbf{5}$, Scheme 2). ${ }^{45}$

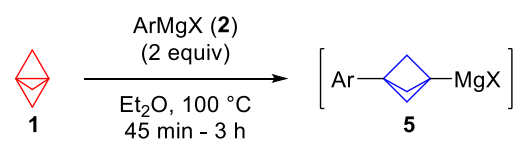

Scheme 2, Knochel's advance on addition of 1 to 2 
With this practical improvement, our aim was to utilize the $\mathrm{BCP}$ Grignard reagent in a one pot procedure for the synthesis of aldehydes. To our delight, our first experiments, with orthoformate gave the BCP ortoformate in moderate yield (7, Scheme 3). Unfortunately, it required an additional heating at $100{ }^{\circ} \mathrm{C}$ and was accompanied with inseparable by-products. Hydrolyzation of the acetal with $\mathrm{TFA} / \mathrm{H}_{2} \mathrm{O}$ provided the aldehyde, but the yields and purity were inconsistent throughout the experiments. Thus, we have turned our attention to the Bouveault aldehyde synthesis. ${ }^{46}$ This process utilizes dimethylformamide (8) as a formyl-group source. DMF is not only conveniently accessible, also the hydrolysis upon workup provided the desired aldehyde product smoothly. This method was proceeded in just a few minutes, and eliminated the need of further heating, that might lead to degradation is some starting materials.

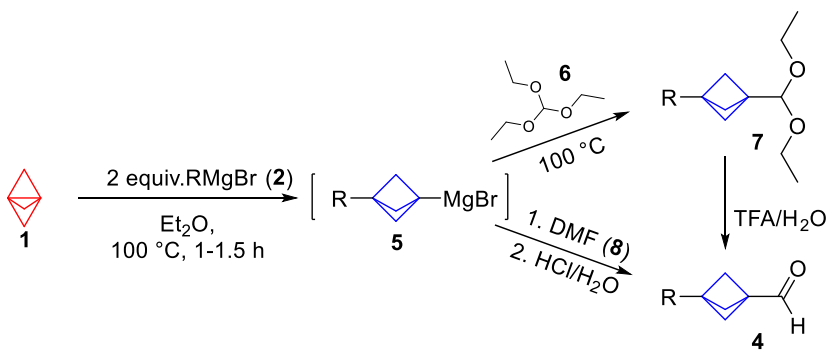

Scheme 3. A practical route to $\mathrm{BCP}$ aldehyde

Upon optimization, we have found that Knochel's conditions proved to be reliable and robust. As working above boiling point of the solvent might be a safety issue with conventional screw-cap vials, an induction-heated reactor was used for both steps. ${ }^{47}$ The addition of Grignard reagents to the DMF proceeded smoothly at room temperature in 15 minutes. The adduct provided the aldehyde on acidic workup.

Having a simple and fast procedure to the BCP-aldehydes we aimed to explore the versatility of the process. The two-stage procedure proved to be generally utilizable for the synthesis of various arylbicyclopentyl-aldehydes. $4 a$ was prepared in the induction reactor with $61 \%$ yield (Scheme 4). For testing the scalability of the method, 10 and $25 \mathrm{mmol}$ reactions were set up in regular pressure flasks, with oil-bath heating. To our delight, the method was easily scalable and gave slightly higher yields ( 81 and $78 \%$ ) on gram scale without the need of the special reactor.

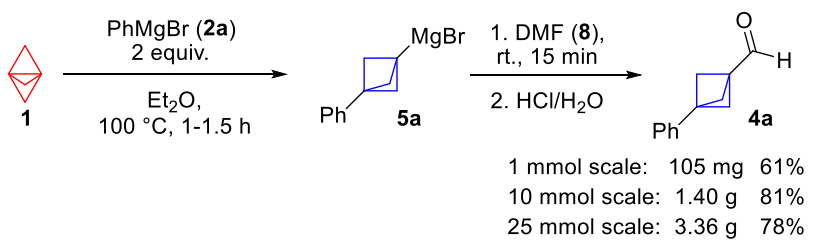

Scheme 4, One-pot synthesis of $4 a$

To establish the scope of the reactions, first simple alkyl substituted products, $\mathbf{4 b}$ and $\mathbf{4 d}$ have been synthesized in good yields (Scheme 5). BCP aldehydes from dihalo substituted arenes 4chloro- and 4-fluorobromobenzene $(\mathbf{4 d}, \mathbf{4 e})$, that are compatible with Grignard reagents gave desired products in moderate yields. Methoxy and trifluoromethoxy functional group containing products $\mathbf{4 h}$ and $\mathbf{g}$ were synthesized in good and excellent yields. TMS and alkynyl TMS groups of $\mathbf{4 h}$ and $\mathbf{j}$ might provide further possibility of transformation. Dialkylamine $\mathbf{4} \mathbf{j}$ was synthesized in $86 \%$ yield. Sterical hindrance plays a negative role in the yield, as seen from comparing the yields of $\mathbf{4 k}$ and 4l, most likely in the step of incorporating the BCP scaffold. Smaller hindrance was not an issue, as exemplified in the case of $4 \mathrm{n}$ and 40.

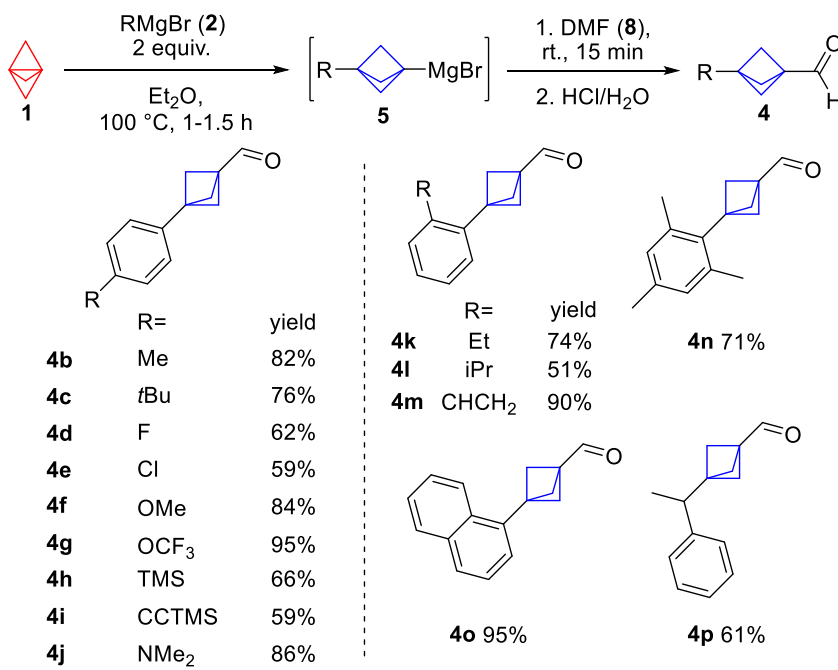

Scheme 5, Simple synthesis of BCP aldehydes. Isolated yields on 1 mmol scale.

Reactions with alkyl Grignard reagents provided products according to GCMS analysis, but the separation of these compounds from the byproducts were unsuccessful in our hands, the only exception being the phenethyl BCP (4p).

Albeit the aldehydes are known for their ability to oxidize, the $\mathrm{BCP}$-aldehydes were stable in the freezer for months. After a 1year storage, we were able to recover more than $90 \%$ of the sample mass of $\mathbf{4 a}$ after column chromatography. Most of the products has a pleasant flower-like scent.

To broaden the availability of readily usable BCP containing scaffolds our aim was to synthesize alkynyl bearing bicyclopentanes, as only a few syntheses was found in the literature. ${ }^{40,48-53}$ This is surprising, as alkynyls are amongst the most versatile functionalities in organic chemistry. With our available BCPaldehydes and Ohira-Bestmann reagent, terminal alkynes were obtained in good to excellent yields (Scheme 6).

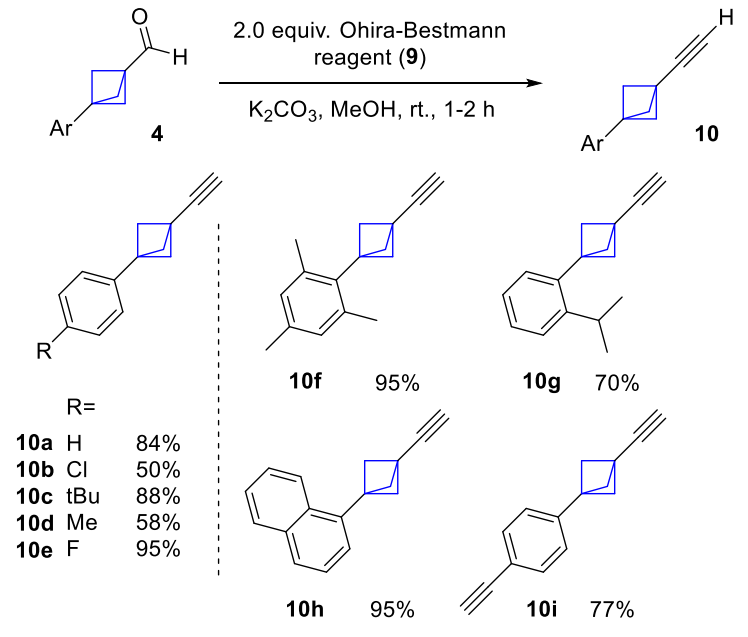

Scheme 6, Synthesis of BCP acetylenes. Isolated yields on 0.5 mmol scale 
These BCP containing building blocks allow us to gain more complexity (Scheme 7). For example, through $\mathrm{A}^{3}$ reaction $^{54}$ a simple reaction with phenylacetylene (11) and morpholine (12) provided the product 13a in good yield. An interesting product has been obtained by reacting one of our BCP alkynes (10a), resulting in a double $\mathrm{BCP}$ containing molecule $(\mathbf{1 3 b})$. As further exploring the boundaries of possible molecule types, a Sonogashira-Larock type synthesis of BCP-benzofurans 15a and b was achieved. To our knowledge these are the first described molecules in this class.

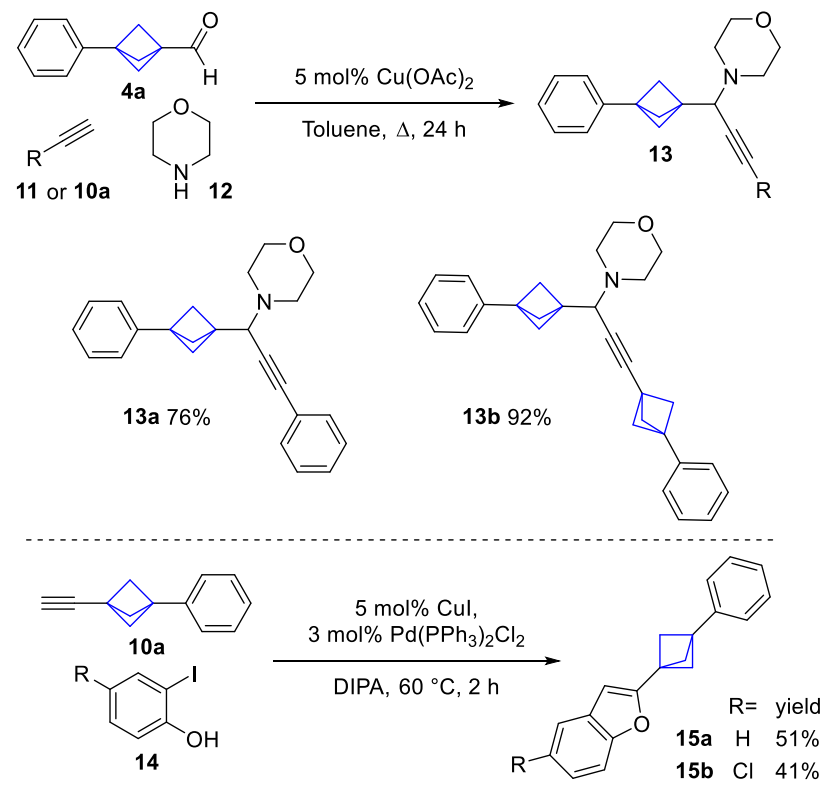

Scheme 7, Application of BCP aldehydes and alkynes

In conclusion, we have provided an easy access to storable, versatile [1.1.1]bicyclopentane containing building blocks, that can be converted to various molecules. We hope that this simple procedure will decrease the activation barrier for chemists to further explore the beauty of BCP chemistry and produce more useful compounds for medicinal chemistry applications and more.

\section{ASSOCIATED CONTENT}

\section{AUTHOR INFORMATION}

\section{Corresponding Author}

*E-mail:tolnai@chem.elte.hu

\section{Orcid}

Gergely L. Tolnai: 0000-0002-5253-5117

\section{Notes}

The authors declare no competing financial interest.

\section{ACKNOWLEDGMENT}

This project was founded by the Hungarian National Research, Development and Innovation Office (OTKA-FK-134947, UNKP-20365, TKP 2020-IKA05). G. L. T. has a Bolyai Scholarship of Hungarian Academy of Sciences (BO/536/20). D. L. is grateful for Servier, for Servier-Beregi scholarship. We are grateful to Dr. L. Burai and S. Szabó (Servier) for HRMS measurements.

\section{REFERENCES}

1. Lovering, F.; Bikker, J.; Humblet, C., Escape from Flatland: Increasing Saturation as an Approach to Improving Clinical Success. $J$. Med. Chem. 2009, 52 (21), 6752-6756.

2. Lovering, F., Escape from Flatland 2: complexity and promiscuity. MedChem Comm 2013, 4 (3), 515-519.

3. Fischer, J.; Ganellin, C. R.; Rotella, D. P., Analogue-based Drug Discovery III. Wiley: 2012.

4. Meanwell, N. A., Synopsis of Some Recent Tactical Application of Bioisosteres in Drug Design. J. Med. Chem. 2011, 54 (8), 2529-2591.

5. Locke, G. M.; Bernhard, S. S. R.; Senge, M. O., Nonconjugated Hydrocarbons as Rigid-Linear Motifs: Isosteres for Material Sciences and Bioorganic and Medicinal Chemistry. Chem. Eur. J. 2019, 25 (18), 4590-4647.

6. Stepan, A. F.; Subramanyam, C.; Efremov, I. V.; Dutra, J. K.; O'Sullivan, T. J.; DiRico, K. J.; McDonald, W. S.; Won, A.; Dorff, P. H.; Nolan, C. E.; Becker, S. L.; Pustilnik, L. R.; Riddell, D. R.; Kauffman, G. W.; Kormos, B. L.; Zhang, L.; Lu, Y.; Capetta, S. H.; Green, M. E.; Karki, K.; Sibley, E.; Atchison, K. P.; Hallgren, A. J.; Oborski, C. E.; Robshaw, A. E.; Sneed, B.; O'Donnell, C. J., Application of the Bicyclo[1.1.1]pentane Motif as a Nonclassical Phenyl Ring Bioisostere in the Design of a Potent and Orally Active $\gamma$ Secretase Inhibitor. J. Med. Chem. 2012, 55 (7), 3414-3424.

7. Auberson, Y. P.; Brocklehurst, C.; Furegati, M.; Fessard, T. C.; Koch, G.; Decker, A.; La Vecchia, L.; Briard, E., Improving Nonspecific Binding and Solubility: Bicycloalkyl Groups and Cubanes as para-Phenyl Bioisosteres. ChemMedChem 2017, 12 (8), 590-598.

8. Measom, N. D.; Down, K. D.; Hirst, D. J.; Jamieson, C.; Manas, E. S.; Patel, V. K.; Somers, D. O., Investigation of a Bicyclo[1.1.1]pentane as a Phenyl Replacement within an LpPLA2 Inhibitor. ACS Med. Chem. Lett. 2017, 8 (1), 43-48.

9. Mannaioni, G.; Attucci, S.; Missanelli, A.; Pellicciari, R.; Corradetti, R.; Moroni, F., Biochemical and electrophysiological studies on (S)-(+)-2-(3'-carboxybicyclo[1.1.1]pentyl)-glycine (CBPG), a novel mGlu5 receptor agonist endowed with mGlu1 receptor antagonist activity. Neuropharmacology 1999, 38 (7), 917-926.

10. Goh, Y. L.; Cui, Y. T.; Pendharkar, V.; Adsool, V. A., Toward Resolving the Resveratrol Conundrum: Synthesis and in Vivo Pharmacokinetic Evaluation of BCP-Resveratrol. ACS Med. Chem. Lett. 2017, 8 (5), 516-520.

11. Nicolaou, K. C.; Vourloumis, D.; Totokotsopoulos, S.; Papakyriakou, A.; Karsunky, H.; Fernando, H.; Gavrilyuk, J.; Webb, D.; Stepan, A. F., Synthesis and Biopharmaceutical Evaluation of Imatinib Analogues Featuring Unusual Structural Motifs. ChemMedChem 2016, 11 (1), 31-37.

12. Pellicciari, R.; Raimondo, M.; Marinozzi, M.; Natalini, B.; Costantino, G.; Thomsen, C., (S)-(+)-2-(3'Carboxybicyclo[1.1.1]pentyl)- glycine, a Structurally New Group I Metabotropic Glutamate Receptor Antagonist. J. Med. Chem. 1996, 39 (15), 2874-2876

13. Filosa, R.; Marinozzi, M.; Costantino, G.; Hermit, M. B.; Thomsen, C.; Pellicciari, R., Synthesis and biological evaluation of (2S)- and (2R)-2-(3'-phosphonobicyclo[1.1.1]pentyl)glycines as novel group III selective metabotropic glutamate receptor ligands. Bioorg. Med. Chem. 2006, 14 (11), 3811-3817.

14. Pellicciari, R.; Filosa, R.; Fulco, M. C.; Marinozzi, M.; Macchiarulo, A.; Novak, C.; Natalini, B.; Hermit, M. B.; Nielsen, S.; Sager, T. N.; Stensbøl, T. B.; Thomsen, C., Synthesis and Preliminary Biological Evaluation of 2'-Substituted 2-(3'Carboxybicyclo[1.1.1]pentyl)glycine Derivatives as Group I Selective Metabotropic Glutamate Receptor Ligands. ChemMedChem 2006, 1 (3), 358-365.

15. Costantino, G.; Maltoni, K.; Marinozzi, M.; Camaioni, E.; Prezeau, L.; Pin, J.-P.; Pellicciari, R., Synthesis and biological evaluation of 2-(3'-(1H-tetrazol-5-yl)bicyclo[1.1.1]pent-1-yl)glycine (S-TBPG), a novel mGlu1 receptor antagonist. Bioorg. Med. Chem. 2001, 9 (2), 221-227. 
16. Kanazawa, J.; Uchiyama, M., Recent Advances in the Synthetic Chemistry of Bicyclo[1.1.1]pentane. Synlett 2019, 30 (01) $1-11$.

17. Mykhailiuk, P. K., Saturated bioisosteres of benzene: where to go next? Org. Biomol. Chem. 2019, 17 (11), 2839-2849.

18. Turkowska, J.; Durka, J.; Gryko, D., Strain release - an old tool for new transformations. Chem. Commun. 2020, 56 (43), 5718 5734.

19. Dilmaç, A. M.; Spuling, E.; de Meijere, A.; Bräse, S., Propellanes-From a Chemical Curiosity to "Explosive" Materials and Natural Products. Angew. Chem., Int. Ed. 2017, 56 (21), 5684-5718.

20. Shelp, R. A.; Ciro, A.; Pu, Y.; Merchant, R. R.; Hughes, J. M. E.; Walsh, P. J., Strain-release 2-azaallyl anion addition/borylation of [1.1.1]propellane: synthesis and functionalization of benzylamine bicyclo[1.1.1]pentyl boronates. Chem. Sci. 2021, 12 (20), 7066-7072.

21. Yu, S.; Jing, C.; Noble, A.; Aggarwal, V. K., 1,3Difunctionalizations of [1.1.1]Propellane via 1,2-Metallate Rearrangements of Boronate Complexes. Angew. Chem., Int. Ed. 2020, 59 (10), 3917-3921.

22. VanHeyst, M. D.; Qi, J.; Roecker, A. J.; Hughes, J. M. E.; Cheng, L.; Zhao, Z.; Yin, J., Continuous Flow-Enabled Synthesis of Bench-Stable Bicyclo[1.1.1]pentane Trifluoroborate Salts and Their Utilization in Metallaphotoredox Cross-Couplings. Org. Lett. 2020, 22 (4), 1648-1654.

23. Fawcett, A.; Pradeilles, J.; Wang, Y.; Mutsuga, T.; Myers, E. L.; Aggarwal, V. K., Photoinduced decarboxylative borylation of carboxylic acids. Science 2017, 357 (6348), 283.

24. Caputo, D. F. J.; Arroniz, C.; Dürr, A. B.; Mousseau, J. J.; Stepan, A. F.; Mansfield, S. J.; Anderson, E. A., Synthesis and applications of highly functionalized 1-halo-3-substituted bicyclo[1.1.1]pentanes. Chem. Sci. 2018, 9 (23), 5295-5300.

25. Goh, Y. L.; Tam, E. K. W.; Bernardo, P. H.; Cheong, C. B.; Johannes, C. W.; William, A. D.; Adsool, V. A., A New Route to Bicyclo[1.1.1]pentan-1-amine from 1-Azido-3iodobicyclo[1.1.1]pentane. Org. Lett. 2014, 16 (7), 1884-1887.

26. Gianatassio, R.; Lopchuk, J. M.; Wang, J.; Pan, C.-M.; Malins, L. R.; Prieto, L.; Brandt, T. A.; Collins, M. R.; Gallego, G. M.; Sach, N. W.; Spangler, J. E.; Zhu, H.; Zhu, J.; Baran, P. S., Strainrelease amination. Science 2016, 351 (6270), 241-246.

27. Thirumoorthi, N. T.; Jia Shen, C.; Adsool, V. A., Expedient synthesis of 3-phenylbicyclo[1.1.1]pentan-1-amine via metal-free homolytic aromatic alkylation of benzene. Chem. Commun. 2015, 51 (15), 3139-3142

28. Zhang, X.; Smith, R. T.; Le, C.; McCarver, S. J.; Shireman, B. T.; Carruthers, N. I.; MacMillan, D. W. C., Copper-mediated synthesis of drug-like bicyclopentanes. Nature 2020, 580 (7802), 220226.

29. Kim, J. H.; Ruffoni, A.; Al-Faiyz, Y. S. S.; Sheikh, N. S.; Leonori, D., Divergent Strain-Release Amino-Functionalization of [1.1.1]Propellane with Electrophilic Nitrogen-Radicals. Angew. Chem., Int. Ed. 2020, 59 (21), 8225-8231.

30. Hughes, J. M. E.; Scarlata, D. A.; Chen, A. C. Y.; Burch, J. D.; Gleason, J. L., Aminoalkylation of [1.1.1]Propellane Enables Direct Access to High-Value 3-Alkylbicyclo[1.1.1]pentan-1-amines. Org. Lett. 2019, 21 (17), 6800-6804.

31. Kanazawa, J.; Maeda, K.; Uchiyama, M., Radical Multicomponent Carboamination of [1.1.1]Propellane. J. Am. Chem. Soc. 2017, 139 (49), 17791-17794.

32. Zarate, C.; Ardolino, M.; Morriello, G. J.; Logan, K. M.; Kaplan, W. P.; Torres, L.; Li, D.; Chen, M.; Li, H.; Su, J.; Fuller, P.; Maddess, M. L.; Song, Z. J., Development of Scalable Routes to 1Bicyclo[1.1.1]pentylpyrazoles. Org. Process Res. Dev. 2021, 25 (3), 642-647.

33. Kondo, M.; Kanazawa, J.; Ichikawa, T.; Shimokawa, T.; Nagashima, Y.; Miyamoto, K.; Uchiyama, M., Silaboration of [1.1.1]Propellane: A Storable Feedstock for Bicyclo[1.1.1]pentane Derivatives. Angew. Chem., Int. Ed. 2020, 59 (5), 1970-1974.

34. Matsunaga, T.; Kanazawa, J.; Ichikawa, T.; Harada, M.; Nishiyama, Y.; Duong, N. T.; Matsumoto, T.; Miyamoto, K.; Uchiyama, M., $\alpha$-Cyclodextrin Encapsulation of Bicyclo[1.1.1]pentane
Derivatives: A Storable Feedstock for Preparation of [1.1.1]Propellane. Angew. Chem., Int. Ed. 2021, 60 (5), 2578-2582.

35. Ripenko, V.; Vysochyn, D.; Klymov, I.; Zhersh, S.; Mykhailiuk, P. K., Large-Scale Synthesis and Modifications of Bicyclo[1.1.1]pentane-1,3-dicarboxylic Acid (BCP). J. Org. Chem. 2021.

36. Trongsiriwat, N.; Pu, Y.; Nieves-Quinones, Y.; Shelp, R. A.; Kozlowski, M. C.; Walsh, P. J., Reactions of 2-Aryl-1,3-Dithianes and [1.1.1]Propellane. Angew. Chem., Int. Ed. 2019, 58 (38), 13416-13420.

37. Shelp, R. A.; Walsh, P. J., Synthesis of BCP Benzylamines From 2-Azaallyl Anions and [1.1.1]Propellane. Angew. Chem., Int. Ed. 2018, 57 (48), 15857-15861.

38. Mikhailiuk, P. K.; Afonin, S.; Chernega, A. N.; Rusanov, E. B.; Platonov, M. O.; Dubinina, G. G.; Berditsch, M.; Ulrich, A. S.; Komarov, I. V., Conformationally Rigid Trifluoromethyl-Substituted $\alpha$-Amino Acid Designed for Peptide Structure Analysis by Solid-State 19F NMR Spectroscopy. Angew. Chem., Int. Ed. 2006, 45 (34), 5659 5661 .

39. Kokhan, S. O.; Tymtsunik, A. V.; Grage, S. L.; Afonin, S.; Babii, O.; Berditsch, M.; Strizhak, A. V.; Bandak, D.; Platonov, M. O.; Komarov, I. V.; Ulrich, A. S.; Mykhailiuk, P. K., Design, Synthesis, and Application of an Optimized Monofluorinated Aliphatic Label for Peptide Studies by Solid-State 19F NMR Spectroscopy. Angew. Chem., Int. Ed. 2016, 55 (47), 14788-14792.

40. Kokhan, S. O.; Valter, Y. B.; Tymtsunik, A. V.; Komarov, I. V.; Grygorenko, O. O., Bicyclo[1.1.1]pentane-Derived Building Blocks for Click Chemistry. Eur. J. Org. Chem. 2017, 2017 (43), 64506456.

41. Zhao, J.-X.; Chang, Y.-X.; He, C.; Burke, B. J.; Collins, M. R.; Del Bel, M.; Elleraas, J.; Gallego, G. M.; Montgomery, T. P.; Mousseau, J. J.; Nair, S. K.; Perry, M. A.; Spangler, J. E.; Vantourout, J. C.; Baran, P. S., 1,2-Difunctionalized bicyclo[1.1.1]pentanes: Longsought-after mimetics for ortho/meta substituted arenes. Proc. Natl. Acad. Sci. 2021, 118 (28), e2108881118.

42. Pritz, S.; Pätzel, M.; Szeimies, G.; Dathe, M.; Bienert, M., Synthesis of a chiral amino acid with bicyclo[1.1.1]pentane moiety and its incorporation into linear and cyclic antimicrobial peptides. Org. Biomol. Chem. 2007, 5 (11), 1789-1794.

43. Daniel Rehm, J. D.; Ziemer, B.; Szeimies, G., A Facile Route to Bridgehead Disubstituted Bicyclo[1.1.1]pentanes Involving Palladium-Catalyzed Cross-Coupling Reactions. Eur. J. Org. Chem. 1999, 1999 (9), 2079-2085.

44. De Meijere, A.; Messner, M.; Vill, V., Liquid Crystalline Bicyclo[1.1.1]pentane Derivatives. Mol. Cryst. Liq. Cryst. 1994, 257 (1), 161-167.

45. Makarov, I. S.; Brocklehurst, C. E.; Karaghiosoff, K.; Koch, G.; Knochel, P., Synthesis of Bicyclo[1.1.1]pentane Bioisosteres of Internal Alkynes and para-Disubstituted Benzenes from [1.1.1]Propellane. Angew. Chem., Int. Ed. 2017, 56 (41), 12774-12777.

46. Wang, Z., Bouveault Aldehyde Synthesis. In Comprehensive Organic Name Reactions and Reagents, Wang, Z., Ed. pp 490-492.

47. Obermayer, D.; Znidar, D.; Glotz, G.; Stadler, A.; Dallinger, D.; Kappe, C. O., Design and Performance Validation of a Conductively Heated Sealed-Vessel Reactor for Organic Synthesis. $J$. Org. Chem. 2016, 81 (23), 11788-11801.

48. Wu, Z.; Xu, Y.; Zhang, H.; Wu, X.; Zhu, C., Radicalmediated sulfonyl alkynylation, allylation, and cyanation of propellane. Chem. Commun. 2021, 57 (49), 6066-6069.

49. Schwab, P. F. H.; Noll, B. C.; Michl, J., Synthesis and Structure of Trigonal and Tetragonal Connectors for a "Tinkertoy" Construction Set. J. Org. Chem. 2002, 67 (16), 5476-5485.

50. Bunz, U.; Szeimies, G., Synthesis of 1alkynylbicyclo[1.1.1]pentanes. Tetrahedron Lett. 1989, 30 (16), 2087 2088.

51. Kaleta, J.; Nečas, M.; Mazal, C., 1,3Diethynylbicyclo[1.1.1]pentane, a Useful Molecular Building Block Eur. J. Org. Chem. 2012, 2012 (25), 4783-4796.

52. Lemouchi, C.; Iliopoulos, K.; Zorina, L.; Simonov, S.; Wzietek, P.; Cauchy, T.; Rodríguez-Fortea, A.; Canadell, E.; Kaleta, J.; Michl, J.; Gindre, D.; Chrysos, M.; Batail, P., Crystalline Arrays of 
Pairs of Molecular Rotors: Correlated Motion, Rotational Barriers, and Space-Inversion Symmetry Breaking Due to Conformational Mutations. J. Am. Chem. Soc. 2013, 135 (25), 9366-9376.

53. Mansfield, S. J.; Smith, R. C.; Yong, J. R. J.; Garry, O. L.; Anderson, E. A., A General Copper-Catalyzed Synthesis of Ynamides from 1,2-Dichloroenamides. Org. Lett. 2019, 21 (8), 2918-2922.
54. Peshkov, V. A.; Pereshivko, O. P.; Van der Eycken, E. V., A walk around the A3-coupling. Chem. Soc. Rev. 2012, 41 (10), 37903807. 